\title{
Milk, coronary heart disease and mortality
}

\author{
A R Ness, G Davey Smith, C Hart
}

\begin{abstract}
Study objective-To study the association between reported milk consumption and cardiovascular and all cause mortality. Design-A prospective study of 5765 men aged 35-64 at the time of examination. Setting-Workplaces in the west of Scotland between 1970 and 1973.

Participants-Men who completed a health and lifestyle questionnaire, which asked about daily milk consumption, and who attended for a medical examination. Main results-150 (2.6\%) men reported drinking more than one and a third pints a day, Some $2977(51.6 \%)$ reported drinking between a third and one and a third pints a day and $2638(45.8 \%)$ reported drinking less than a third of a pint a day. There were a total of 2350 deaths over the 25 year follow up period, of which 892 deaths were attributed to coronary heart disease. The relative risk, adjusted for socioeconomic position, health behaviours and health status for deaths from all causes for men who drank one third to one and a third pints a day versus those who drank less than a third of a pint was 0.90 (95\% CI $0.83,0.97)$. The adjusted relative risk for deaths attributed to coronary heart disease for men who drank one third to one and a third pints a day versus those who drank less than one third of a pint was 0.92 (95\% CI 0.81, 1.06).

Conclusions-No evidence was found that men who consumed milk each day, at a time when most milk consumed was full fat milk, were at increased risk of death from all causes or death from coronary heart disease.

(F Epidemiol Community Health 2001;55:379-382)
\end{abstract}

The effects on population health of increased intake of milk are uncertain. In the first half of this century increased milk production and consumption was encouraged, particularly in children, as it was believed to improve vitality and shown to increase growth in children. ${ }^{1}$ After the second world war the epidemic of coronary heart disease (CHD) and the accumulating evidence that increased saturated fat intake, by increasing blood cholesterol levels, increased risk of coronary disease, ${ }^{23}$ led to a review of policy. Increasingly, in recent years, the public has been encouraged both to reduce their milk intake and to switch to low fat milk products in order to reduce their fat consumption. ${ }^{4}$ Recent studies, however, have suggested that increased fat intake may be protective for stroke. ${ }^{5}$
Ecological analyses have shown high correlations between milk intake and coronary mortality rates $^{67}$ (which tend to be at least as strong as those observed for saturated fat). The focus of many observational studies on dietary constituents rather than food items means that the individual based data available on milk and cardiovascular risk are limited. Given the relative lack of prospective data on the association between milk intake, $\mathrm{CHD}$ and other diseases we have analysed the association between milk intake and mortality in a large cohort of men in the west of Scotland on whom we have detailed information regarding important potential confounding factors.

\section{Methods}

This analysis is based on a cohort of 5765 men aged 35-64 at the time of examination recruited from workplaces in the west of Scotland between 1970 and 1973. Full details of the present study population (The Collaborative Study) and the data collection methods have been described previously. ${ }^{8}$

The information collected at baseline included: sociodemographic data, health status measures, information on health related behaviours and measurements recorded at a physical examination. Data are available on the subject's age, their father's occupation and their occupation at the time of screening (coded to social class). Data are also available on the subject's age at leaving full time education, their number of siblings and whether they were regular car drivers. In addition, the home address at the time of screening was retrospectively allocated a postcode, enabling an area-based deprivation category at the time of the 1981 census to be ascertained. Deprivation category varies from 1 (least deprived) to 7 (most deprived). Details of self reported angina from the Rose questionnaire (with angina defined as definite) ${ }^{10}$ and self reported respiratory symptoms from the Medical Research Council questionnaire ${ }^{11}$ are available. Detailed information on smoking and alcohol consumption ${ }^{12}$ was recorded. At examination height, weight, blood pressure and lung function were measured, an electrocardiogram performed and blood drawn for estimation of plasma cholesterol and triglycerides. Forced expiratory volume in one second, $\mathrm{FEV}_{1}$, expressed as a percentage of the expected $\mathrm{FEV}_{1}$ for age and height, was calculated from the subset of healthy participants. ${ }^{9}$

Men were sent a self completed questionnaire. One question asked men how many pints of milk they usually drank each day. The answers to this question were checked when the men attended for screening. The responses to this question were used to allocate men into three groups. Men who drank less than a third 
Table 1 Age adjusted means and proportions of characteristics according to self reported milk consumption at baseline

\begin{tabular}{|c|c|c|c|c|}
\hline & \multicolumn{3}{|c|}{ Pints of milk per day ( 1 pint $=0.568$ litres $)$} & \multirow{2}{*}{$\begin{array}{l}p \text { value for } \\
\text { trend }\end{array}$} \\
\hline & none & one & $>$ than one & \\
\hline Number of men & 2638 & 2977 & 150 & \\
\hline Age $^{\star}$ & 49.0 & 47.7 & 46.2 & 0.0001 \\
\hline Social class I and II (\%) & 30.7 & 33.9 & 31.3 & 0.009 \\
\hline Father's social class I and II (\%) & 12.6 & 14.5 & 16.3 & 0.009 \\
\hline Regular drivers (\%) & 49.0 & 54.2 & 51.2 & 0.0004 \\
\hline Number of siblings & 3.5 & 3.4 & 3.4 & 0.032 \\
\hline Deprivation category 6 and $7(\%)$ & 31.4 & 26.4 & 24.6 & 0.0001 \\
\hline Leave education at 14 years or under & 53.1 & 49.0 & 52.3 & 0.013 \\
\hline Angina $(\%)$ & 6.6 & 6.0 & 1.5 & 0.09 \\
\hline ECG ischaemia (\%) & 5.8 & 5.9 & 3.7 & 0.77 \\
\hline Bronchitis (\%) & 2.4 & 2.0 & 1.3 & 0.20 \\
\hline Never smoker (\%) & 16.9 & 18.1 & 23.8 & 0.08 \\
\hline Current cigarette smoker (\%) & 57.0 & 54.2 & 50.8 & 0.020 \\
\hline Cigarettes per day $\dagger$ & 19.2 & 18.7 & 19.8 & 0.23 \\
\hline Systolic blood pressure $(\mathrm{mm} \mathrm{Hg})$ & 133.9 & 133.9 & 136.1 & 0.45 \\
\hline Diastolic blood pressure $(\mathrm{mm} \mathrm{Hg})$ & 83.9 & 83.8 & 85.0 & 0.68 \\
\hline Cholesterol $(\mathrm{mmol} / \mathrm{l})$ & 5.87 & 5.89 & 5.90 & 0.46 \\
\hline Height $(\mathrm{cm})$ & 172.2 & 173.4 & 173.5 & 0.0001 \\
\hline Body mass index $\left(\mathrm{kg} / \mathrm{m}^{2}\right)$ & 25.2 & 25.1 & 25.5 & 0.50 \\
\hline Triglycerides $(\mathrm{mmol} / \mathrm{l}) \ddagger$ & 1.37 & 1.37 & 1.32 & 0.82 \\
\hline FEV1 score $(\%)$ & 93.5 & 94.8 & 98.0 & 0.002 \\
\hline Units of alcohol per week & 12.7 & 11.4 & 12.1 & 0.009 \\
\hline
\end{tabular}

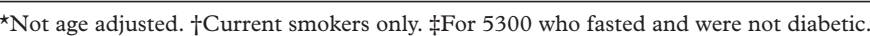

Table 2 Twenty five year relative rates of mortality by self reported milk consumption at baseline (in three categories) in 5765 men from the Collaborative study

\begin{tabular}{|c|c|c|c|c|}
\hline & \multicolumn{3}{|c|}{ Pints per day ( 1 pint $=0.568$ litres $)$} & \multirow[b]{2}{*}{ Trend $^{\star}$} \\
\hline & none & one & $>$ than one & \\
\hline \multicolumn{5}{|l|}{ All cause } \\
\hline Number of deaths & 1194 & 1108 & 48 & \\
\hline Age adjusted relative rate & 1 & $0.85(0.78,0.92)$ & $0.78(0.58,1.04)$ & $\mathrm{p}=0.0001$ \\
\hline Fully adjusted relative rate† & 1 & $0.90(0.83,0.97)$ & $0.81(0.61,1.09)$ & $\mathrm{p}=0.005$ \\
\hline \multicolumn{5}{|c|}{ Cardiovascular disease (390-459) } \\
\hline Number of deaths & 607 & 586 & 19 & \\
\hline Age adjusted relative rate & 1 & $0.89(0.79,1.00)$ & $0.61(0.39,0.97)$ & $\mathrm{p}=0.009$ \\
\hline Fully adjusted relative rate $\nmid$ & 1 & $0.93(0.83,1.04)$ & $0.64(0.40,1.00)$ & $\mathrm{p}=0.05$ \\
\hline \multicolumn{5}{|l|}{ Coronary heart disease } \\
\hline Number of deaths & 446 & 431 & 15 & \\
\hline Age adjusted relative rate & 1 & $0.89(0.78,1.01)$ & $0.65(0.39,1.08)$ & $\mathrm{p}=0.025$ \\
\hline \multicolumn{4}{|l|}{ Stroke } & $\mathrm{p}=0.11$ \\
\hline Number of deaths & 98 & 94 & 4 & \\
\hline Age adjusted relative rate & 1 & $0.92(0.69,1.22)$ & $0.86(0.32,2.34)$ & $\mathrm{p}=0.52$ \\
\hline Fully adjusted relative ratef & 1 & $0.93(0.70,1.24)$ & $0.84(0.31,2.30)$ & $\mathrm{p}=0.58$ \\
\hline \multicolumn{5}{|l|}{ Lung cancer } \\
\hline Number of deaths & 140 & 119 & 7 & \\
\hline Age adjusted relative rate & 1 & $0.77(0.61,0.99)$ & $0.95(0.44,2.03)$ & $\mathrm{p}=0.07$ \\
\hline Fully adjusted relative rate $\ddagger$ & 1 & $0.84(0.66,1.08)$ & $0.94(0.44,2.02)$ & $\mathrm{p}=0.22$ \\
\hline \multicolumn{5}{|l|}{ Other cancer } \\
\hline Number of deaths & 230 & 207 & 11 & \\
\hline Age adjusted relative rate & 1 & $0.82(0.68,0.98)$ & $0.91(0.50,1.66)$ & $\mathrm{p}=0.05$ \\
\hline Fully adjusted relative rate $\ddagger$ & 1 & $0.83(0.69,1.01)$ & $0.88(0.48,1.62)$ & $\mathrm{p}=0.08$ \\
\hline \multicolumn{5}{|l|}{ Other } \\
\hline Number of deaths & 280 & 257 & 11 & \\
\hline Age adjusted relative rate & 1 & $0.84(0.71,0.99)$ & $0.76(0.42,1.39)$ & $\mathrm{p}=0.035$ \\
\hline Fully adjusted relative rate $\ddagger$ & 1 & $0.92(0.77,1.09)$ & $0.84(0.46,1.54)$ & $\mathrm{p}=0.28$ \\
\hline
\end{tabular}

†Over the groups. †Adjusted for age, smoking, diastolic blood pressure, cholesterol, body mass index, adjusted $\mathrm{FEV}_{1}$, social class, father's social class, education, deprivation category, siblings, car user, angina, ECG ischaemia, bronchitis and alcohol consumption. ¥Adjusted for age, smoking, body mass index, adjusted $\mathrm{FEV}_{1}$, social class, father's social class, education, deprivation category, siblings, car user, bronchitis and alcohol consumption.

of a pint a day (< 0.189 litres/day) were allocated to the category called "none". Men who drank more than a third of a pint and less than one and a third pint $(>0.189$ and $<0.757$ litres/day) were allocated to the category "one pint per day". Men who drank more than one and a third pints ( $>0.757$ litres/day) a day were allocated to the category "more than one pint per day".

In 1977 about half of the cohort (2686) returned for a repeat screening that involved identical data collection to the initial screening.

Mortality over a 25 year follow up period has been ascertained from flagging at the National
Health Service Central Registry in Edinburgh, which also provides death certificates coded according to the ninth revision of the International Classification of Diseases (ICD).

Continuous variables have been age standardised using PROC GLM, in the SAS system, with tests for trend for age adjusted means being obtained through PROC REG. Categorical variables have been age standardised by the direct method and tests for trend performed in PROC LOGIST. Proportional hazards coefficients and their standard errors were calculated using PROC PHREG with adjustment for age and other risk factors by including terms for these in the proportional hazards models. Exponentiated hazards coefficients are taken as indicators of relative rates of mortality. For missing values of variables a dummy variable was created and used in the adjustments. Only for father's social class was there a considerable number of missing values. Cronbach's $\alpha$ was calculated to compare the reliability of responses to the same question on frequency of milk consumption five years apart.

\section{Results}

Some $45.8 \%$ of the men reported drinking less than a third of a pint a day and $51.6 \%$ reported drinking more than a third of a pint a day and less than one and a third pints day. Only $2.6 \%$ reported drinking over one and a third pints per day. The characteristics of different groups of milk drinkers are shown in table 1. Non-milk drinkers tended to be shorter, older and of lower socioeconomic position and were more likely to be current cigarette smokers, to drink more alcohol and to have worse lung function than milk drinkers. There was little difference in blood pressure, cholesterol concentration, triglyceride concentration, body mass index and prevalence of ECG ischaemia between the milk consumption groups.

Over the 25 year follow up period 2350 men died, 892 of CHD, 196 of stroke, 266 of lung cancer, 448 of other cancers and 548 of other causes. The association between reported milk consumption and mortality is shown in table 2 . Milk consumption was inversely associated with all cause, cardiovascular, coronary heart disease, non-lung cancer and other mortality. As milk consumption was associated with a more favourable profile of socioeconomic and behavioural risk factors for mortality the relative rates were adjusted for a comprehensive range of relevant potential confounding factors. These adjustments attenuated slightly the apparent protective effect of milk consumption but the associations with all cause mortality and cardiovascular mortality remained statistically significant at conventional levels. The analyses were repeated splitting the follow up period into deaths in the first 10 years and deaths in the next 15 years. The results were essentially unchanged for all cause, cardiovascular and coronary mortality (data not shown).

Cronbach's $\alpha$ was calculated for the 2686 men who were screened twice, on average five 
years apart. This yielded a value of 0.59 , representing a reasonable level of stability in reported milk consumption.

\section{Discussion}

In this prospective study of Scottish working men we have found no evidence that regular consumers of milk are at increased risk of death from heart disease or death from all causes. In fact the age adjusted risk of mortality from all causes and mortality from cardiovascular disease was lower in those drinking between one third and one and a third pints a day. Though adjustment attenuated the relative risk slightly it remained statistically significant for deaths from all causes. The risk of death from stroke was also reduced in regular milk drinkers, though this reduction was not statistically significant and the confidence intervals were wide.

It is likely that there is measurement error in our assessment of usual milk consumption, which was based on a single question about milk drunk. The question did not ask men about milk used in food preparation. Neither did it ask men about intake of skimmed or semi-skimmed milk though data from the British National Food Survey suggest that consumption of reduced fat milks was unusual in the 1970s. The reasonable agreement between repeat measures some years apart suggests that this question was reproducible. Any measurement error associated with our measure of milk consumption will have reduced our ability to detect any real milk mortality associations. Such measurement error is random and though it might explain a failure to find an adverse association with coronary death or death from all causes in regular milk drinkers it is unlikely to explain the apparent protective association observed.

Confounding is a possible alternative explanation for the associations we have observed as men who consume milk regularly may be healthier or live healthier lives. The observations that regular milk consumers have better risk profiles and that regular milk consumption is associated with reduced risk of death from a number of different causes (both coronary heart disease and cancers unrelated to smoking) support this notion. However, adjustment for a large number of potential confounding variables results in only modest attenuation of the observed associations. Though we cannot discount confounding as an explanation for these findings it seems unlikely that residual confounding is masking a markedly increased risk of coronary death, or death from all causes, in regular milk drinkers.

If regular milk consumption is not associated with increased risk of death and particularly coronary death (as predicted by the classic diet-heart hypothesis) why might this be? One possible explanation is that milk does not raise serum cholesterol (despite its high saturated fat content). Observations that the Maasai (a semi-nomadic people living in East Africa) who consume large quantities of milk have low serum cholesterol concentrations led to speculation that milk might contain a cholesterol
KEY POINTS

- In the past milk consumption was encouraged. More recently it has been discouraged because of concerns about its fat content

- We found no evidence that milk consumption was associated with increased risk of coronary death or death from all causes.

- Milk drinkers were healthier in several respects. Residual confounding may explain the failure to observe increased mortality in milk drinkers.

lowering factor or factors. Further studies in the Maasai, however, suggest that their calorie and milk intake were overestimated. ${ }^{14}$ Some trials of increased milk intake in free living humans have reported reduced serum cholesterol concentrations, ${ }^{15}$ but controlled feeding studies, despite their small size, seem to confirm that increased milk intake does indeed increase serum cholesterol concentrations. ${ }^{16} 17$ Though milk contains other factors that may increase coronary risk, such as lactose ${ }^{18}$ it also contains some that may reduce coronary heart disease risk, such as calcium. ${ }^{19}$ Also if milk consumption in adulthood is associated with milk consumption in childhood, this might explain the association. Increased milk in childhood leads to increased growth ${ }^{20}$ and thus increased height. And increased leg length in childhood and height in adulthood is associated with reduced coronary and all cause mortality. $^{2122}$

A necropsy study showed a high prevalence of coronary hear disease in peptic ulcer patients treated with a milk diet in the UK and the USA. ${ }^{23}$ In the UK arm of the study $18 \%$ of necropsied ulcer patients on a milk diet had evidence of myocardial infarction compared with $3 \%$ of necropsied ulcer patients not given a milk diet $(\mathrm{p}<0.01) .{ }^{23}$ A case-control study of women in Italy reported a modest (nonsignificant) reduction in risk of myocardial infarction with increased milk consumption-an odds ratio of 0.9 in women drinking milk daily compared with those drinking milk weekly. ${ }^{24}$

We are aware of seven prospective studies that have examined the association between milk consumption and coronary, cerebrovascular or all cause mortality. In a cohort study of over 25000 Seventh Day Adventists the relative risk of coronary death was 0.94 $(p<0.05)$ in men drinking two glasses a day versus none but for women the relative risk was 1.11 (and not statistically significant).$^{25}$ In the Caerphilly cohort study there was a striking inverse association between milk consumption and coronary hear disease risk. ${ }^{26}$ In the 2818 men the unadjusted relative risk of major ischaemic disease was 0.12 (95\% CI 0.03 to 0.53 ) for men drinking one or more pints a day compared with those drinking none. ${ }^{26}$ Data from the British Regional Heart study suggested that the apparent protective effect observed in the Caerphilly study might be a 
result of men with existing coronary heart disease reducing their milk intake because of their illness, thus generating an association between milk intake and future coronary events. ${ }^{27}$ It was also suggested that confounding by socioeconomic position, cigarette smoking and other coronary heart disease risk factors might have accentuated the association between milk consumption and coronary heart disease incidence. Nevertheless, even after adjustment the relative risk of fatal and non-fatal cardiovascular disease among the 7735 men in the British Regional Heart Study was 0.88 for men who drank milk and had milk on their cereal compared with those who did not. ${ }^{27}$ The Basel study of 2974 male employees of three pharmaceutical companies after eight years reported that: "Milk consumption and coronary atherosclerosis at autopsy (1980 mortality follow-up) shows a trend for an inverse correlation $(p=0.12) .{ }^{\prime 28}$ In the Honolulu Heart Study milk consumption was associated with reduced risk of thromboembolic stroke-in 3150 men of Japanese ancestry who reported drinking $16 \mathrm{oz}$ of milk per day had half the stroke risk of non-milk drinkers. ${ }^{29}$ Temporal analyses from Japan have also shown that increased milk consumption is associated with decreased stroke mortality. ${ }^{30}$ In a study of over $10000 \mathrm{UK}$ vegetarians the death rate ratio for deaths from all causes was reduced in those who drank more than half a pint day compared with those who drank less than half a pint a day: 87 (95\% CI 68 to 113). And in those that drank half a pint a day the death rate ratio compared with those that drank less than half a pint day was 70 (95\% CI 55 to 88). The death rate ratio for ischaemic heart disease was 150 (95\% CI 81 to 278 ) in those drinking more than half a pint a day but $76(95 \%$ CI 40 to 143) for those drinking half a pint a day. ${ }^{31}$ Finally, in a cohort of over 34000 middle aged Iowa women the adjusted risk of coronary death in those in the top quartile of consumption of dairy products (excluding butter) versus the lowest quartile was $0.94(95 \%$ CI 0.66 to $1.35, \mathrm{p}$ for trend $=0.64) .^{32}$

So in summary we have found no evidence that men who reported regular consumption of milk were at increased risk of death from coronary heart disease, or death from all causes. While the modest protective associations we observed for deaths from all causes and deaths from coronary heart disease could be explained by residual confounding by dietary or non-dietary exposures our data do not support the notion that regular consumption of milk is hazardous to health. Victor Hawthorne was responsible for the original screening and
we thank him for continuing interest. Charles Gillis, David Hole and Pauline MacKinnon are also thanked for their support.

Funding: this study was provided with funding by a grant from the NHS Management Executive Cardiovascular Disease and Stroke Research and Development Initiative.

Conflicts of interest: none.

1 Milk Nutrition Committee. Milk and nutrition. New experiments reported to the milk nutrition committee. Part II the effects of dietary supplements of pasteurised and raw milk on growth and health of school children (interim report). Reading: growth and health of school
Poynder and Son, 1938.

2 Stamler J. Established major coronary risk factors. In: Marmot M, Elliott P, eds. Coronary heart disease epidemiology: from aetiology to public health. Oxford: OUP, 1992.

3 Willett W. Nutritional epidemiology. New York: OUP, 1990.

4 Cardiovascular Review Group of the Committee on Medical Aspects of Food Policy. Nutrutional aspects of cardiovascular disease. London: HMSO, 1994

5 Gillman MW, Cupples LA, Millen BE, et al. Inverse association of dietary fat with development of ischaemic stroke in men. FAMA 1997;278:2145-50.

6 Segall JJ. Is milk a coronary health hazard? Br f Prev Soc Med 1977;31:81-5.

7 Knox EG. Foods and diseases. British Fournal of Preventive and Social Medicine 1977;31:71-80.

8 Davey Smith G, Hart CL, Hole D, et al. Education and occupational social class: which is the more important indicator of mortality risk? 7 Epidemiol Community Health 1998;52:153-60.

9 Davey Smith G, Hart C, Blane D, et al. Lifetime socioeconomic position and mortality: prospective observational study. BMF 1997;314:547-52.

10 Hart CL, Watt GCM, Davey Smith G, et al. Pre-existing ischaemic heart disease and ischaemic heart disease mortality in women compared with men. Int $\mathcal{f}$ Epidemiol 1997;26:508-15.

11 Medical Research Council. Definition and classification of chronic bronchitis for epidemiological purposes. Lancet 1965;i:775-9.

12 Hart CL, Davey Smith G, Hole DJ, et al. Alcohol consumption and mortality from all causes, coronary heart disease and stroke: results from a prospective cohort study of Scottish men with 21 years of follow up. BM7 1999;318:17259.

13 Charlton J, Quaife K. Trends in diet 1841-1994. In: Charlton J, Murphy M. The health of adult Britain 1841-1994. Vol ton J, Murphy M. The health of adult Britain

14 Gibney MJ, Burstyn PG. Milk, serum cholesterol, and the Maasai. Atherosclerosis 1980;35:339-43.

15 Howard AN, Marks J. Effect of milk products on serum-cholesterol. Lancet 1979;ii:957.

16 Roberts DCK, Truswell AS, Sullivan DR, et al. Milk, plasma cholesterol and controls in nutritional experiments. Atherosclerosis 1982;42:323-5.

17 Howard AN, Marks J. The lack of evidence for a hypocholesterolaemic factor in milk. Atherosclerosis 1982;45:243-7.

18 Segall JJ. Dietary lactose as a possible risk factor for ischaemic heart disease: review of epidemiology. Int 7 Cardiol 1994;46:197-207.

19 Cappuccio FP, Elliott P, Allender PS, et al. Epidemiologic association between dietary calcium intake and blood pressure: a meta-analysis of published data. Am F Epidemiol 1995;142:935-45.

20 Baker IA, Elwood PC, Hughes J, et al. A randomised controlled trial of the effect of the provision of free school milk on the growth of children. $\mathcal{F}$ Epidemiol Community Health 1980;34:31-4.

21 Gunnell D, Davey Smith G, Frankel S, et al. Childhood leg length and adult mortality: follow up of the Carnegie (Boyd Orr) survey of diet and health in pre-war Britain. $\mathcal{F}$ Epidemiol Community Health 1998;52:142-52.

22 Powles JW, Ruth D. Diet mortality associations: an overview. In: Walqvist Ml, Vobecky JS, eds. Medical practice of preventive nutrition. London: Smith-Gordon, 1994.

23 Briggs RD, Rubenberg ML, O’Neal RM, et al. Myocardial infarction in patients treated with a Sippy and other high-milk diets: an autopsy study of fifteen hospitals in the USA and Great Britain. Circulation 1960;21:538-42.

24 Gramenzi A, Gentile A, Fasoli M, et al. Association between certain foods and risk of acute myocardial infarction in women. BMF 1990;300:771-3.

25 Snowdon DA, Phillips RL, Fraser GE. Meat consumption and fatal ischemic heart disease. Prev Med 1984;13:490-500.

26 Elwood PC, Yarnell JWG, Burr ML, et al. Epidemiological studies of cardiovascular disease: progress report VII. Cardiff: MRC Epidemiology Unit, 1991.

27 Shaper AG, Wannamethee G, Walker M. Milk, butter and heart disease. BMF 1991;302: 785-6.

28 Stahelin HB, Eichholzer M, Gey KF. Nutritional factors correlating with cardiovascular disease: results of the Basel study. Bibl Nutr Dieta 1992;49:24-35.

29 Abbott RD, Curb JD, Rodriguez BL, et al. Effect of dietary calcium and milk consumption on risk of thromboembolic stroke in older middle-aged men: The Honolulu heart program. Stroke 1996;27:813-18.

30 Kimura N. Changing patterns of coronary heart disease, stroke and nutrient intake in Japan. Prev Med 1983;12:2227.

31 Mann JI, Appleby PN, Key TJA, et al. Dietary determinants of ischaemic heart disease in health conscious individuals. Heart 1997;78:450-5.

32 Bostick RM, Kushi LH, Wu Y, et al. Relation of calcium, vitamin $\mathrm{D}$, and dairy food intake to ischaemic heart disease mortality among postmenopausal women. Am f Epidemiol 1999;149:151-61. 